\title{
Removal of Cadmium and Lead from Aqueous Solution by Hydroxyapatite/Chitosan Hybrid Fibrous Sorbent: Kinetics and Equilibrium Studies
}

\author{
Soyeon Park, ${ }^{1}$ Allan Gomez-Flores, ${ }^{1}$ Yong Sik Chung, ${ }^{2}$ and Hyunjung Kim ${ }^{1}$ \\ ${ }^{1}$ Department of Mineral Resources and Energy Engineering, Chonbuk National University, 567 Baekje-daero, \\ Deokjin-gu, Jeonju, Jeonbuk 561-756, Republic of Korea \\ ${ }^{2}$ Department of Organic Materials \& Fiber Engineering, Chonbuk National University, 567 Baekje-daero, Deokjin-gu, \\ Jeonju, Jeonbuk 561-756, Republic of Korea
}

Correspondence should be addressed to Yong Sik Chung; psdcolor@jbnu.ac.kr and Hyunjung Kim; kshjkim@jbnu.ac.kr

Received 22 April 2015; Accepted 2 July 2015

Academic Editor: Kaustubha Mohanty

Copyright (c) 2015 Soyeon Park et al. This is an open access article distributed under the Creative Commons Attribution License, which permits unrestricted use, distribution, and reproduction in any medium, provided the original work is properly cited.

Hydroxyapatite (HAp)/chitosan composites were prepared by a coprecipitation method, dropping a mixture of chitosan solution and phosphoric acid solution into a calcium hydroxide solution. Using the HAp/chitosan composites prepared, HAp/chitosan hybrid fibers with various HAp contents were prepared by a wet spinning method. X-ray diffraction and scanning electron microscopy analyses revealed that HAp particles were coated onto the surface of the fiber, and the surface roughness increased with increasing the HAp contents in the fiber. In order to evaluate the heavy metal removal characteristics of the HAp/chitosan hybrid fiber, adsorption tests were conducted and the results were compared with those of bare chitosan fibers. The results showed better performance in heavy metal ion removal for the HAp/chitosan hybrid fiber than the chitosan fiber. As the HAp content in the hybrid fiber increased, the removal efficiency of heavy metal ions also increased due to the increase of the specific surface area of the HAp/chitosan hybrid fiber. Adsorption kinetic and isotherm tests revealed that $\mathrm{Pb}^{2+}$ and $\mathrm{Cd}^{2+}$ adsorption to the hybrid fiber follows pseudo-second-order kinetic and Langmuir-type adsorption, respectively.

\section{Introduction}

Heavy metal contamination occurs in aqueous waste streams in many industries, such as metal plating facilities, mining operations, and tanneries [1-3]. Some metals associated with these activities are cadmium $(\mathrm{Cd})$, lead $(\mathrm{Pb})$, chromium $(\mathrm{Cr})$, and mercury $(\mathrm{Hg})$. These heavy metals are not biodegradable; indeed, they tend to accumulate in living organisms, causing various diseases and disorders. Thus, there is a need to minimize the quantities of these heavy metals that could potentially be dangerous to human health. Removal methods for heavy metals include chemical precipitation, membrane filtration, ion exchange, carbon adsorption, and coprecipitation [3-5].

Hydroxyapatite (HAp), the major component of hard tissue, has properties that include deodorization, protein adhesiveness, bioactivity, and biocompatibility $[6,7]$. HAp also has an ion-exchange property; thus it has been reported to be efficient for the removal of various heavy metal ions such as lead, cobalt, nickel, copper, zinc, and cadmium from aqueous solution [8-12]. However, due to the existence of HAp in the form of powder, separating the suspended HAp particles from aqueous solution after the removal of heavy metal ions is not simple [13]. Additionally, the powder-type of HAp is unlikely applicable to continuous packed-bed systems, which are commonly used in practical scale, due to high pressure drops by high packing density of powder-type of materials [14]. Both of the aforementioned drawbacks lead to the limitation of their industrial application.

As one of the methods to overcome the limitation, a recent study has attempted to utilize HAp/chitosan fibers as a bulk-type adsorbent for heavy metal ions from contaminant water [15]. The major advantages of using HAp/chitosan hybrid fibrous materials are as follows: first, chitosan itself 
has also been used as a heavy metal adsorbent because it has a glucosamine pyranose ring per molecule, which includes amine and hydroxyl groups that exhibit excellent reactivity $[16,17]$. This indicates that if the HAp/chitosan hybrid fibers are successfully prepared, synergetic effect for heavy metals removal by both chitosan and HAp is expected. Second, fibers normally exhibit large specific surface areas, and they also have the advantage of being easy to convert to various forms, such as fabrics, knits, and nonwovens, which would overcome the limitations (e.g., the difficulty in solid/liquid separation, high pressure drop in continuous packed-bed system) of powder-type of adsorbents. However, to the best of our knowledge, no study on the heavy metal removal characteristics of HAp/chitosan hybrid fibers according to the content of HAp has yet been conducted; thus the relevant study is required to better advance our knowledge. Hence, the aim of this study was set to successfully prepare organic/inorganic (HAp/chitosan) hybrid fiber with various HAp contents as adsorbents of heavy metal ions and to systematically investigate the removal characteristics of lead $\left(\mathrm{Pb}^{2+}\right)$ and cadmium $\left(\mathrm{Cd}^{2+}\right)$ in terms of kinetics and equilibrium according to the amount of HAp content in the adsorbents.

\section{Materials and Methods}

2.1. Preparation of Chitosan and HAp/Chitosan Hybrid Fibers. The chitosan used was provided by TaeHun Bio, Co., Ltd., Republic of Korea. The degree of deacetylation was reported by the manufacturer to be $\sim 92 \%$, and the viscosity was $600 \mathrm{cp}$ in $0.5 \mathrm{wt} \%$ chitosan solution. All the chemicals (e.g., acetic acid $\left(\mathrm{CH}_{3} \mathrm{COOH}\right)$, calcium hydroxide $\left(\mathrm{Ca}(\mathrm{OH})_{2}\right)$, phosphoric acid $\left(\mathrm{H}_{3} \mathrm{PO}_{4}\right)$, lead nitrate $\left(\mathrm{Pb}\left(\mathrm{NO}_{3}\right)_{2}\right)$, and cadmium nitrate $\left.\left(\mathrm{Cd}\left(\mathrm{NO}_{3}\right)_{2} \cdot 4 \mathrm{H}_{2} \mathrm{O}\right)\right)$ used were reagent grade. They were used without further purification.

A chitosan aqueous solution of $2 \%(\mathrm{w} / \mathrm{w})$ was prepared by dissolving the chitosan powder into $60 \mathrm{mM}$ acetic acid aqueous solution. Then, the chitosan/phosphoric acid mixture was gradually dropped into $100 \mathrm{mM}$ calcium hydroxide suspension, agitated with a mechanical stirrer at a speed greater than $800 \mathrm{rpm}$, via a pipette at a rate of $3.2 \mathrm{~mL} / \mathrm{min}$. The agitation speed was kept high, more than $800 \mathrm{rpm}$, until the $\mathrm{pH}$ became $9 \pm 0.2$. The reaction temperature was $25^{\circ} \mathrm{C}$. The final slurry, the HAp/chitosan composite, was aged with stirring for $24 \mathrm{~h}$. Then, the precipitate was washed with distilled water several times and freeze-dried. A HAp/chitosan (80/20 as weight ratio) composite was finally prepared [18].

After chitosan at a fixed rate was dissolved in acetic acid aqueous solution, we prepared spinning dopes, where the weight ratios of HAp/chitosan were 0/100, 10/90, 20/80, and $30 / 70$ by adding HAp/chitosan composite $(80 / 20$ as weight ratio). The content of chitosan in the spinning dope was kept at 3\%(w/w). We used the spinning dope with sodium hydroxide solidification extract of $10 \mathrm{wt} \%$ on a wet spinning machine where the $0.1 \mathrm{~mm} \times 300$ hole nozzle was equipped for doing filtration-defoaming. Finally, we obtained HAp/chitosan hybrid fibers with different contents of HAp by the wet spinning method after washing and drying.

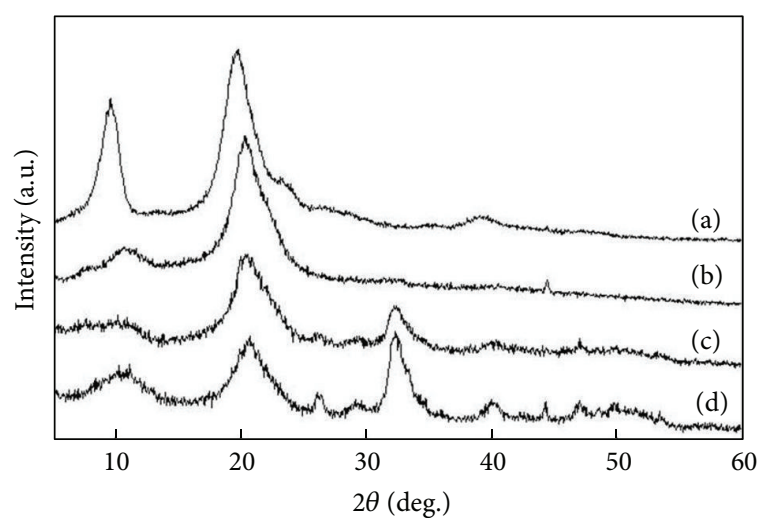

FIGURE 1: XRD patterns of (a) chitosan fiber as well as (b) 10/90, (c) 20/80, and (d) 30/70 HAp/chitosan hybrid fibers.

2.2. Characterizations. Component analysis of the fiber was performed by XRD (a PW1700 X-ray diffractometer, Philips) with $\mathrm{CuK} \alpha$ radiation and in $5^{\circ}-60^{\circ}$ range. For morphological analysis, the chitosan and HAp/chitosan hybrid fiber was examined by scanning electron microscopy (SEM; JSM$6300, \mathrm{JEOL})$. We measured the residual concentration of heavy metal ions in the heavy metal aqueous solutions using inductively coupled plasma-atomic emission spectrometry (ICP-AES).

2.3. Adsorption of Heavy Metal Ions. Heavy metal aqueous solutions, $\mathrm{Pb}^{2+}$ and $\mathrm{Cd}^{2+}$, were prepared at different concentrations $(10 \mathrm{mg} / \mathrm{L}-1000 \mathrm{mg} / \mathrm{L})$. Experiments were conducted by placing a given mass of fiber $(0.1 \mathrm{~g})$ in a $30 \mathrm{~mL}$ glass bottle and pouring heavy metal aqueous solution of $20 \mathrm{~mL}$. The bottle was then covered with a polypropylene lid and placed in a temperature controlled water-bath shaker at $25^{\circ} \mathrm{C}$ for $0.5 \mathrm{~h}-4 \mathrm{~h}$. The suspension $\mathrm{pH}$ was unadjusted $(\sim 6)$. Separation of the heavy metal aqueous solution and fiber was performed simply using tweezers after the adsorption reaction had occurred. The heavy metal aqueous solutions were then stored at $4^{\circ} \mathrm{C}$ until being analyzed.

The metal uptake $q_{e}$ (mg of metal ion/g of HAp/chitosan hybrid fiber) was determined as follows:

$$
q_{e}=\frac{\left(C_{i}-C_{e}\right) V}{W},
$$

where $C_{i}$ and $C_{e}$ are the initial and equilibrium concentrations of heavy metal ion in the aqueous phase $(\mathrm{mg} / \mathrm{L})$, respectively. $V$ is the volume of the solution (L) and $W$ is the amount of used HAp/chitosan hybrid fiber (g).

\section{Results and Discussion}

3.1. Analysis of Chitosan Fiber and HAp/Chitosan Hybrid Fiber with Different HAp Contents. Figure 1 shows the XRD pattern of chitosan fiber and HAp/chitosan hybrid fiber with various contents of HAp in the chitosan matrix. The characteristic peaks of HAp did not appear in the 10/90 HAp/chitosan hybrid fiber, but it was confirmed that the (020) crystal face 
TABLE 1: Removal efficiency of $\mathrm{Pb}^{2+}$ and $\mathrm{Cd}^{2+}$ for the HAp/chitosan hybrid fibers with different HAp contents. For comparison, the removal efficiency for the chitosan fiber is also presented. The initial concentration of $\mathrm{Pb}^{2+}$ and $\mathrm{Cd}^{2+}$ was $10 \mathrm{mg} / \mathrm{L}$ for all tests.

$\mathrm{Pb}^{2+} \quad \mathrm{Cd}^{2+}$

Residual concentration (mg/L) Removal efficiency (\%) Residual concentration (mg/L) Removal efficiency (\%)

\begin{tabular}{lllll}
\hline Chitosan fiber & 5.30 & 47.0 & 7.78 & 22.2 \\
\hline $\begin{array}{l}\text { HA/90 } \\
\text { HAp/chitosan fiber }\end{array}$ & 0.27 & 97.3 & 0.56 & 94.4 \\
\hline $\begin{array}{l}\text { 20/80 } \\
\text { HAp/chitosan fiber }\end{array}$ & 0.08 & 99.2 & 0.14 & 98.6 \\
\hline $\begin{array}{l}\text { 30/70 } \\
\text { HAp/chitosan fiber }\end{array}$ & 0.08 & 99.2 & 0.05 & 99.5 \\
\hline
\end{tabular}

peak of chitosan fiber decreased markedly near $10^{\circ}$, and the (040) crystal face peak near $20^{\circ}$ decreased. Additionally, the (040) crystal face peak near $20^{\circ}$ due to chitosan decreases as the HAp content increased. However, the (002) crystal face peak near $26^{\circ}$ due to the HAp particles included in the HAp/chitosan hybrid fiber appeared. It could be confirmed that the HAp peaks of the (300), (211), and (112) crystal face increased at $32^{\circ}$ [19]. Thus, the XRD results suggest that the material had a crystal structure due to HAp.

In order to visually confirm the change of the surface morphology of the fibers prepared, the surface morphology of both the chitosan fiber and the HAp/chitosan hybrid fiber with various contents of HAp was examined through SEM analysis and compared. Figure 2 shows SEM photographs of chitosan fiber and HAp/chitosan hybrid fibers with different contents of HAp in the chitosan matrix. The surface of the chitosan fiber is smooth (Figures 2(a)-2(b)). However, in the HAp/chitosan hybrid fibers, the surface of the fiber is very rough (Figures 2(c)-2(h)). Particularly, as the HAp content increases in the HAp/chitosan hybrid fiber, the surface of the fiber becomes rougher due to the attached HAp particles on the surface of the fiber. The SEM results clearly support XRD results, indicating the HAp particles were well embedded in the chitosan matrix.

\subsection{Adsorption Characteristics of HAp/Chitosan Hybrid Fiber} in Heavy Metal Aqueous Solutions. Initially, adsorption tests were performed in heavy metal aqueous solution to compare the removal performance for heavy metal ions (i.e., $\mathrm{Pb}^{2+}$ and $\mathrm{Cd}^{2+}$ ) by chitosan fiber and HAp/chitosan hybrid fibers for $2 \mathrm{~h}$. For these tests, HAp/chitosan hybrid fibers with different HAp contents were used. The results are presented in Table 1. The removal efficiency of $\mathrm{Pb}^{2+}$ and $\mathrm{Cd}^{2+}$ was determined to be $47.0 \%$ and $22.2 \%$ for chitosan fibers while $\mathrm{Pb}^{2+}$ and $\mathrm{Cd}^{2+}$ removal efficiency was greater than $94 \%$ for HAp/chitosan hybrid fibers. In addition, the removal efficiency of $\mathrm{Pb}^{2+}$ and $\mathrm{Cd}^{2+}$ tended to increase with increasing HAp content in the HAp/chitosan hybrid fibers. The results indicate that the performance for heavy metal ion removal was much better for HAp/chitosan hybrid fibers than chitosan fiber and was enhanced by increasing HAp content regardless of type of heavy metal ions.
While the comparison study between the bare chitosan fiber and the hybrid fiber clearly reveals that the removal performance of the hybrid fiber is significantly better than the bare fiber even at low heavy metal concentration (i.e., $10 \mathrm{mg} / \mathrm{L}$ ), the difference in heavy metal removal efficiency was minimal among the hybrid fibers. Hence, we further examined the heavy metal ion removal characteristic of the HAp/chitosan hybrid fiber with various HAp contents at higher initial concentration of heavy metal solution (e.g., $100 \mathrm{mg} / \mathrm{L}$ and $1000 \mathrm{mg} / \mathrm{L}$ ) over time. Figures 3(a), 3(c), and 3(e) show the removal efficiency of $\mathrm{Pb}^{2+}$ in heavy metal aqueous solution by $10 / 90,20 / 80$, and $30 / 70$ content ratio of HAp/chitosan hybrid fibers, respectively. The heavy metal ion removal efficiency increased with increasing HAp content in the fiber. Removal with heavy metal aqueous solutions of initial concentrations of $10 \mathrm{mg} / \mathrm{L}$ and $100 \mathrm{mg} / \mathrm{L}$ for $\mathrm{Pb}^{2+}$ was almost complete and equilibrium was reached after $1 \mathrm{~h}$. At an initial concentration of $1000 \mathrm{mg} / \mathrm{L}$ for $\mathrm{Pb}^{2+}$, adsorption equilibrium was reached after $2 \mathrm{~h}$. Figures 3(b), 3(d), and 3(f) show the removal efficiency of $\mathrm{Cd}^{2+}$ in aqueous solution by $10 / 90,20 / 80$, and $30 / 70$ content ratio of HAp/chitosan hybrid fibers, respectively. At initial concentration of $10 \mathrm{mg} / \mathrm{L}$, $100 \mathrm{mg} / \mathrm{L}$, and $1000 \mathrm{mg} / \mathrm{L}$ for $\mathrm{Cd}^{2+}$, adsorption equilibrium was reached after $2 \mathrm{~h}$. The removal efficiency also increased with increasing HAp content in the fiber, which was similar to the trend for $\mathrm{Pb}^{2+}$. The enhanced heavy metal removal by increasing HAp content in the fiber could be attributed to the increase in the specific surface area of the hybrid fiber with increasing HAp contents. Similar observations were also reported by previous studies $[20,21]$. However, the time to reach adsorption equilibrium was retarded compared to $\mathrm{Pb}^{2+}$, indicating that $\mathrm{Pb}^{2+}$ removal was better with hybrid fibers than $\mathrm{Cd}^{2+}$. The greater affinity of $\mathrm{Pb}^{2+}$ than $\mathrm{Cd}^{2+}$ could be attributed to (i) the smaller hydrated radii of $\mathrm{Pb}^{2+}(0.401 \mathrm{~nm})$ than $\mathrm{Cd}^{2+}(0.426 \mathrm{~nm})$, resulting in the $\mathrm{Pb}^{2+}$ having more accessibility to the adsorbent's surface and pores, (ii) the higher electronegativity of $\mathrm{Pb}^{2+}(2.33)$ than $\mathrm{Cd}^{2+}$ (1.69), leading to more strong attraction between $\mathrm{Pb}^{2+}$ and $\mathrm{HAp} /$ chitosan's surface, and (iii) the ionic radii of $\mathrm{Pb}^{2+}$ $(0.118 \mathrm{~nm})$ being larger than $\mathrm{Ca}^{2+}(0.099 \mathrm{~nm})$ while that of $\mathrm{Cd}^{2+}(0.097 \mathrm{~nm})$ being smaller than $\mathrm{Ca}^{2+}$, causing the $\mathrm{Cd}^{2+}$ to have less of a chance to be incorporated into the adsorbent structure $[5,22,23]$. 


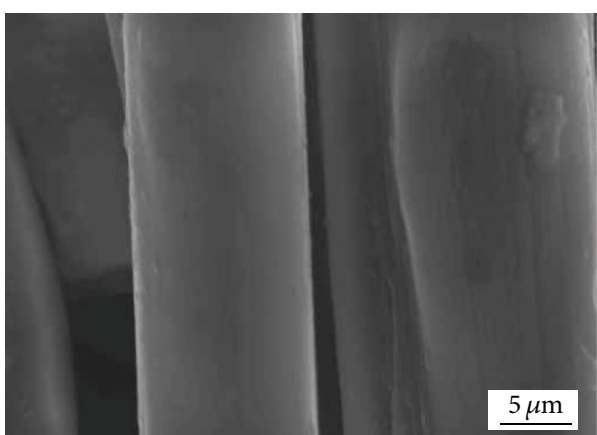

(a)

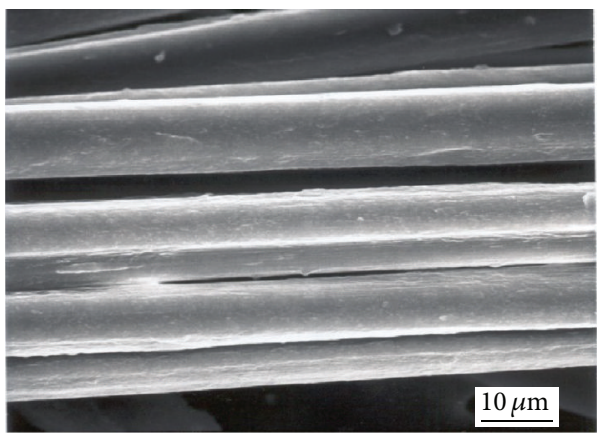

(c)

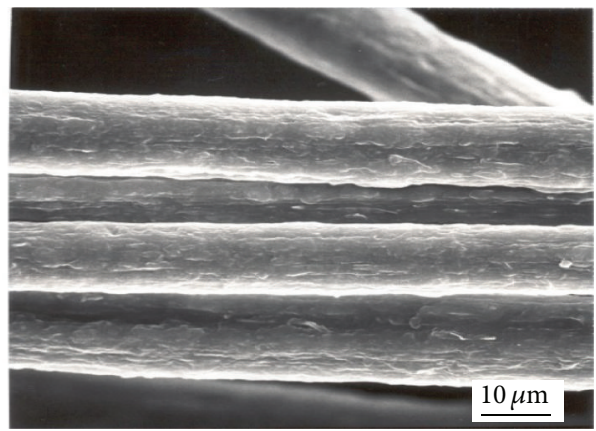

(e)

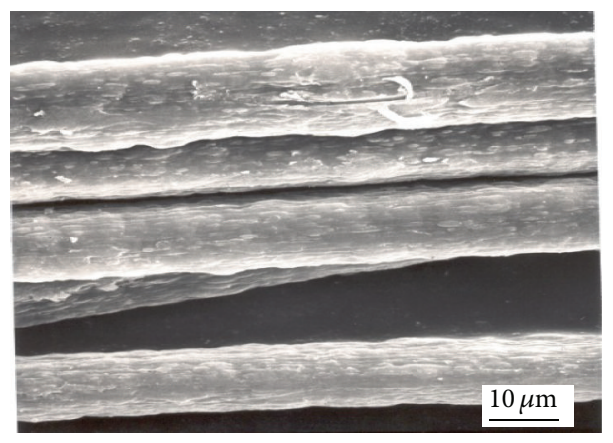

(g)

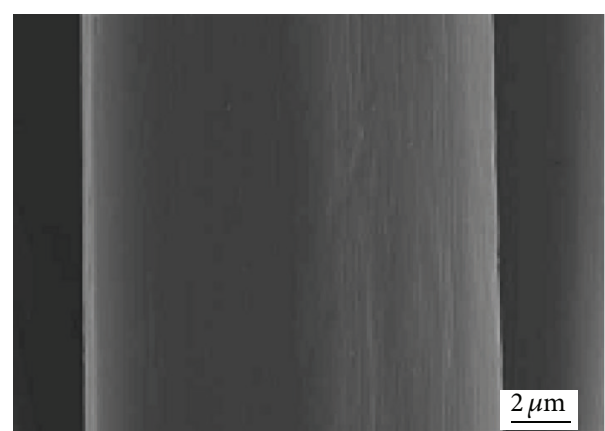

(b)

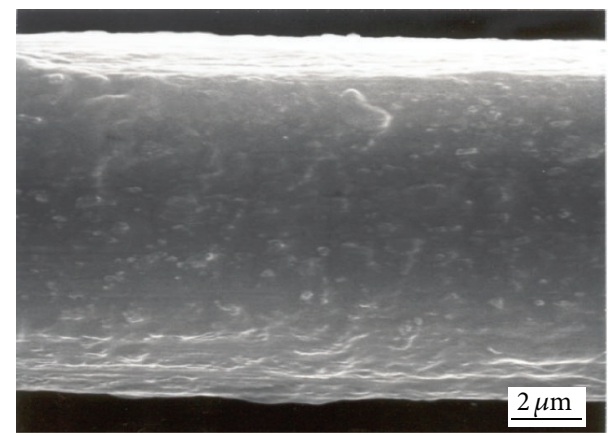

(d)

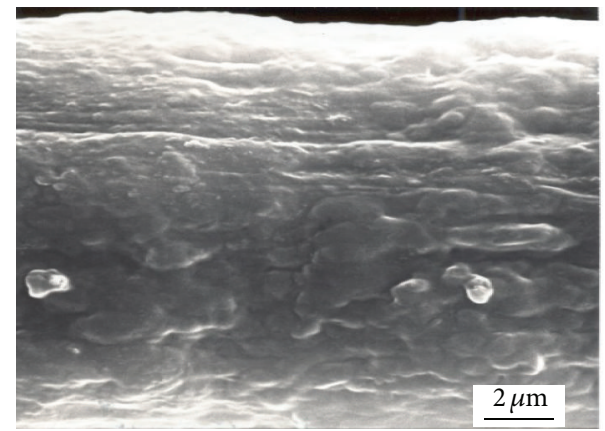

(f)

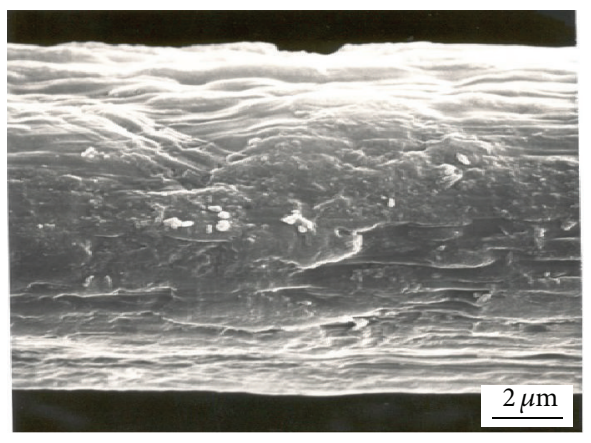

(h)

Figure 2: SEM photographs of chitosan fiber (a and b) as well as 10/90 (c and d), 20/80 (e and f), and 30/70 (g and h) HAp/chitosan hybrid fibers.

3.3. Adsorption Isotherms. To better understand the heavy metal ion adsorption characteristics to the hybrid fiber, we first analyzed the adsorption isotherms that give insight into designing the adsorption system. The isotherms reflect the relationship between the mass of the solute adsorbed per unit mass of adsorbent $\left(q_{e}\right)$ and the solute concentration in bulk solution at equilibrium $\left(C_{e}\right)$ at a constant temperature. For this analysis, Langmuir [24] and Freundlich 

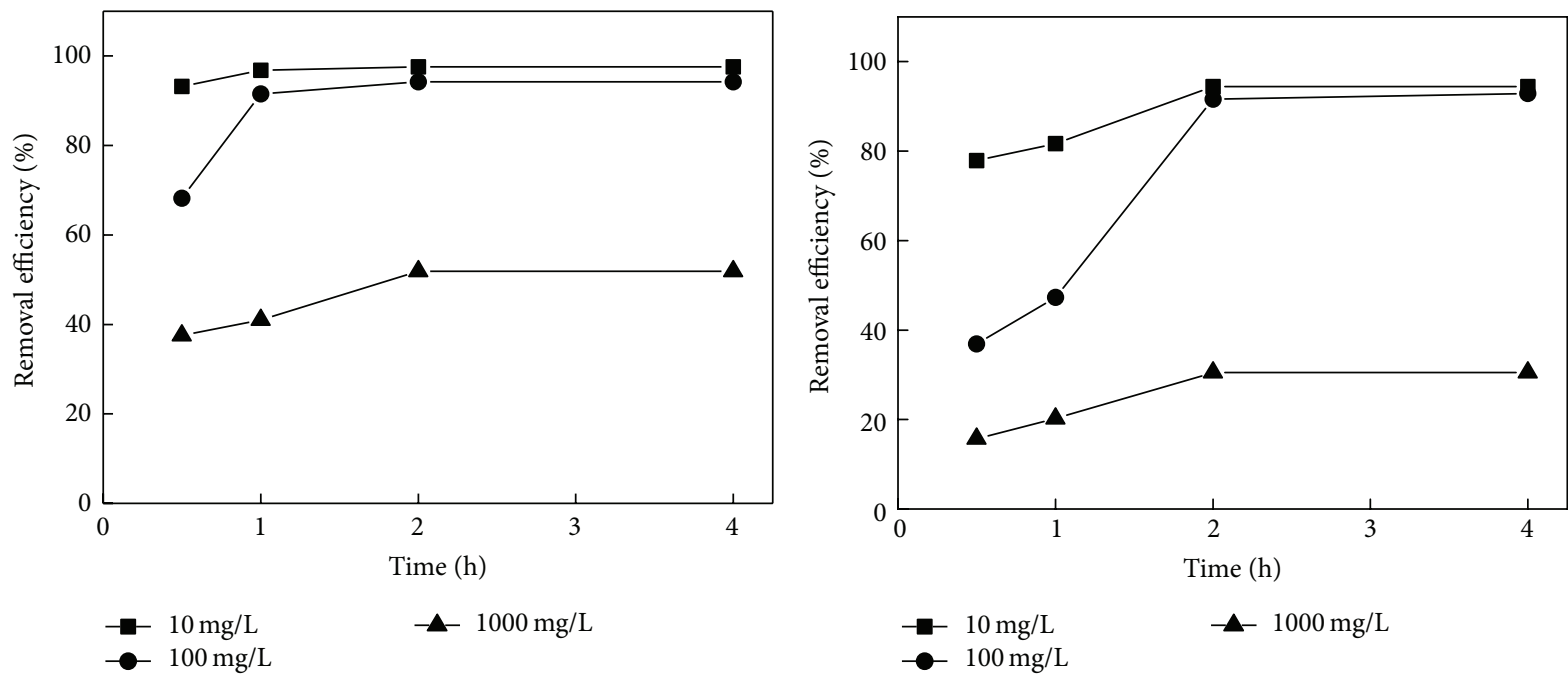

(a) $\mathrm{Pb}^{2+}$
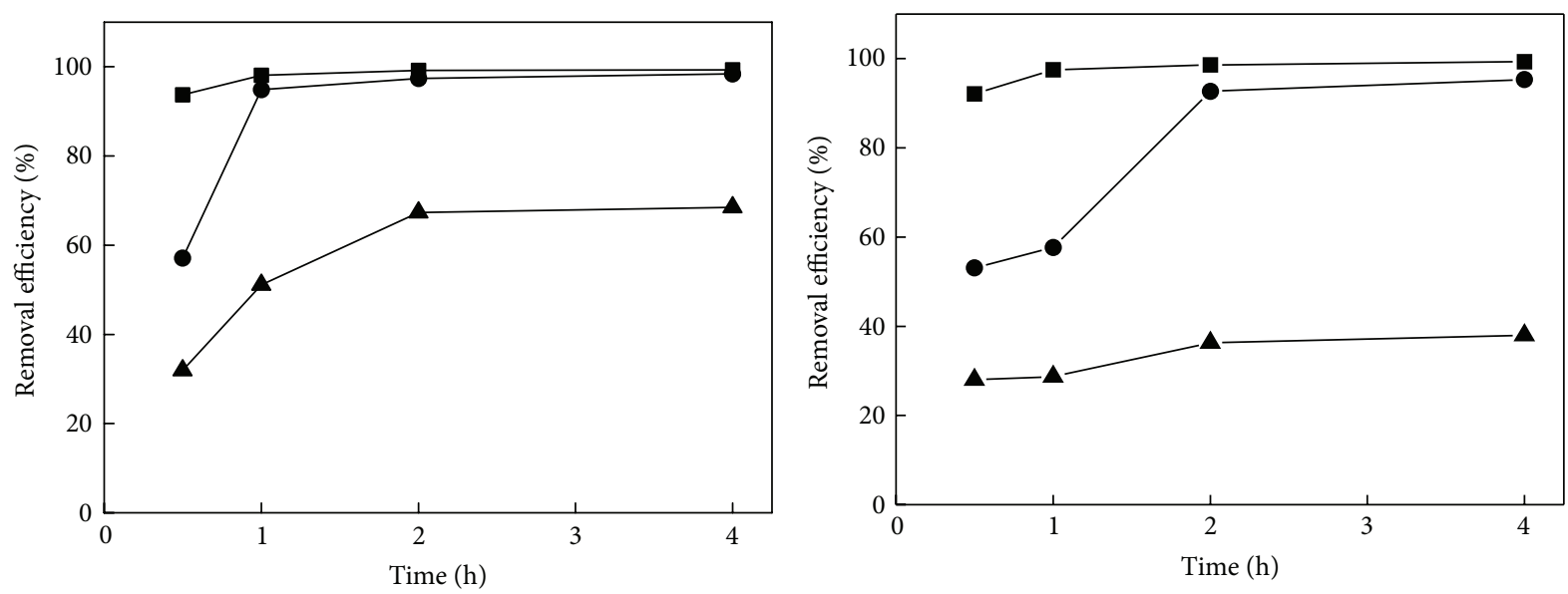

$\rightarrow 10 \mathrm{mg} / \mathrm{L}$

- $1000 \mathrm{mg} / \mathrm{L}$

$100 \mathrm{mg} / \mathrm{L}$

$\longrightarrow 10 \mathrm{mg} / \mathrm{L}$

_ـ $1000 \mathrm{mg} / \mathrm{L}$

(c) $\mathrm{Pb}^{2+}$

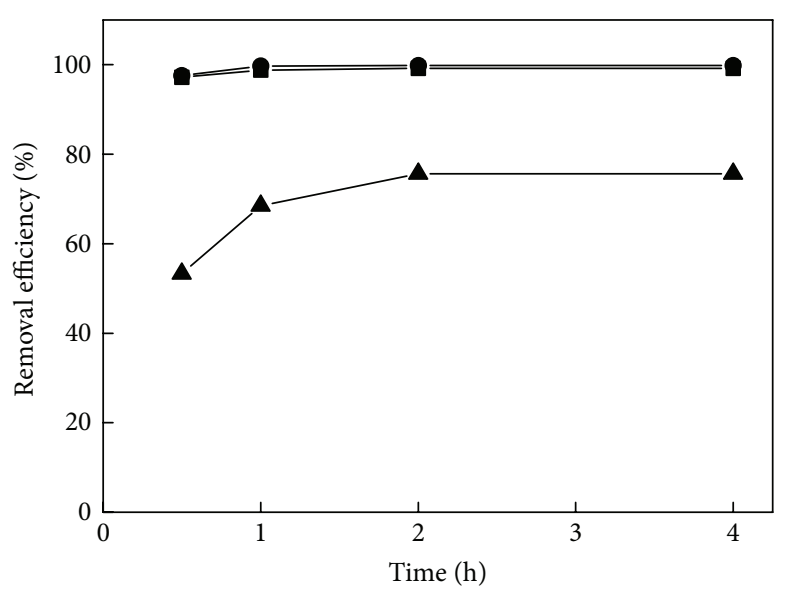

(d) $\mathrm{Cd}^{2+}$

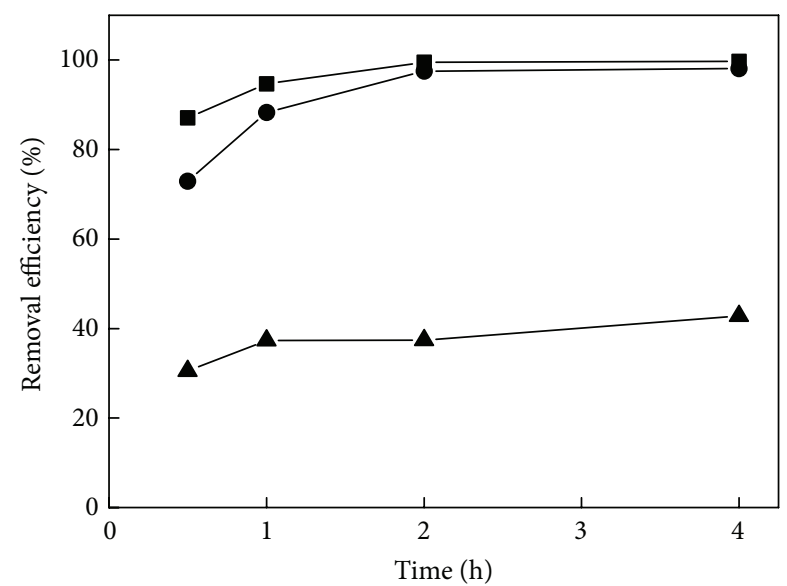

$-10 \mathrm{mg} / \mathrm{L}$
$-100 \mathrm{mg} / \mathrm{L}$

— $1000 \mathrm{mg} / \mathrm{L}$

(e) $\mathrm{Pb}^{2+}$

- $1000 \mathrm{mg} / \mathrm{L}$

- $10 \mathrm{mg} / \mathrm{L}$

$100 \mathrm{mg} / \mathrm{L}$

(f) $\mathrm{Cd}^{2+}$

FIGURE 3: Removal characteristics of $\mathrm{Pb}^{2+}$ and $\mathrm{Cd}^{2+}$ by the HAp/chitosan hybrid fibers with different HAp contents according to initial concentration and reaction time: (a) and (b) 10/90, (c) and (d) 20/80, and (e) and (f) 30/70 HAp/chitosan hybrid fibers. 


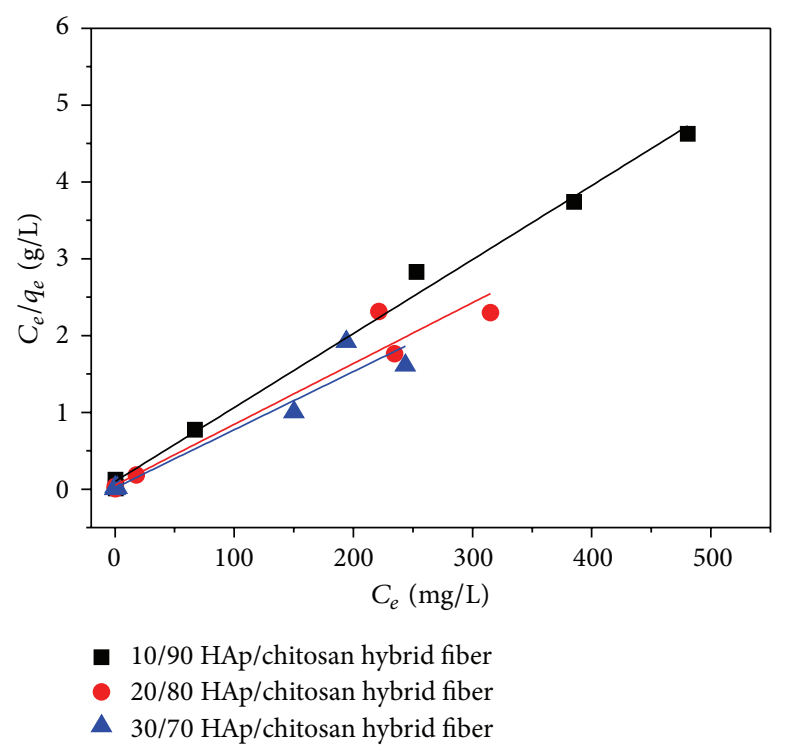

(a)

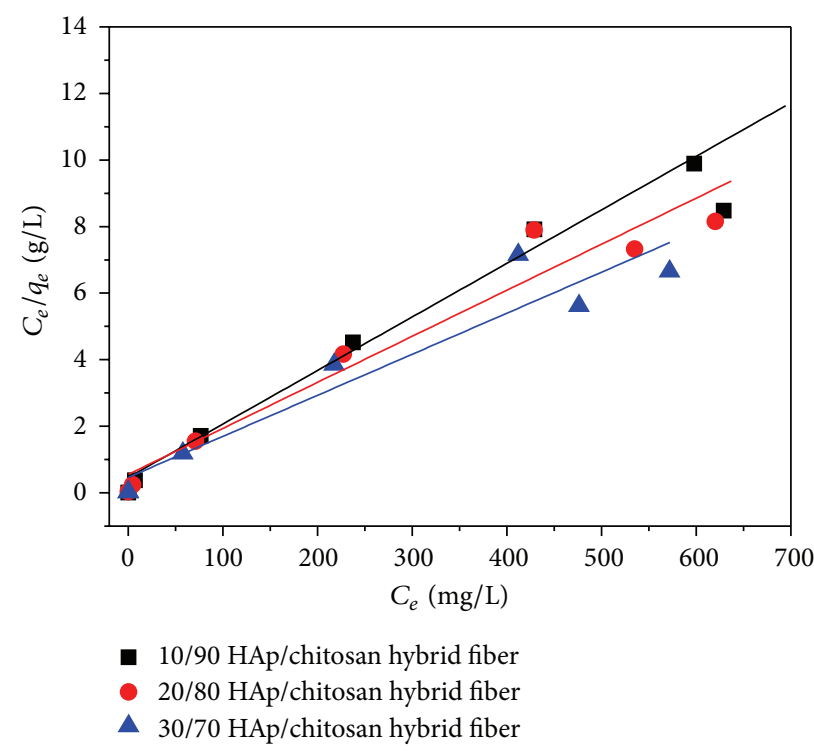

(b)

Figure 4: Langmuir isotherm model for adsorption of (a) $\mathrm{Pb}^{2+}$ and (b) $\mathrm{Cd}^{2+}$ on hybrid fibers with different HAp/chitosan ratio (10/90 (square), 20/80 (circle), and 30/70 (triangle)).

[25] isotherm models were employed. Langmuir adsorption isotherm assumes monolayer adsorption of solutes onto a surface of adsorbent with a finite number of identical sites and can be expressed as

$$
\frac{C_{e}}{q_{e}}=\left(\frac{1}{b q_{\max }}\right)+\left(\frac{1}{q_{\max }}\right) C_{e},
$$

where $C_{e}$ is concentration of metal ions in bulk solution at equilibrium $(\mathrm{mg} / \mathrm{L}), q_{e}$ is the amount of metal ions adsorbed on unit mass of adsorbent at equilibrium $\left(\mathrm{mg} / \mathrm{g}\right.$ ), and $q_{\max }$ and $b$ represent adsorption capacity $(\mathrm{mg} / \mathrm{g})$ and adsorption energy (L/mg), respectively.

Figures 4(a) and 4(b) show the linear plots of $C_{e} / q_{e}$ versus $C_{e}$ for different types of adsorbents, which are used to determine the value of $q_{\max }$ and $b$. The values obtained are given in Table 2. The $r^{2}$ values indicate that Langmuir isotherm fairly well predicts the adsorption process of both heavy metal ions by the HAp/chitosan hybrid fibers with different HAp contents. In addition, regardless of the type of heavy metal ions, the highest $q_{\max }$ was observed for the 30/70 HAp/chitosan hybrid fiber that has the greatest HAp content. This indicates that the heavy metal ion adsorption by hybrid fibers is enhanced as the amount of HAp increases.

The Freundlich isotherm is known to well describe heterogeneous system for nonideal adsorption. The experimental data on $\mathrm{Pb}^{2+}$ and $\mathrm{Cd}^{2+}$ adsorption were fitted to the Freundlich adsorption isotherm [25], which can be expressed as

$$
\ln q_{e}=\ln K_{F}+\left(\frac{1}{n}\right) \ln C_{e}
$$

where $K_{F}$ and $n$ represent adsorption capacity $(\mathrm{mg} / \mathrm{g}$ $\left.(\mathrm{mg} / \mathrm{L})^{-1 / n}\right)$ and the intensity of adsorption.

Figures 5(a) and 5(b) show the Freundlich plots $\left(\ln q_{e}\right.$ versus $\ln C_{e}$ ) for various types of hybrid fibers, and the $K_{F}$, $n$, and $r^{2}$ values are provided in Table 2. The $r^{2}$ values for all cases indicate that the adsorption process is not predictable by the Freundlich isotherm. Consequently, the results for the analysis of adsorption isotherms suggest that Langmuir adsorption isotherm shows a better fit with the experimental data observed in this study compared with the Freundlich isotherm. This result indicates that the surface of the hybrid fibers possesses equal energy for heavy metal ion adsorption regardless of the HAp content, suggesting that the enhanced adsorption with increasing HAp contents is likely due to the increase of specific surface area of the hybrid fiber instead of the difference in the nature of materials between HAp and chitosan.

3.4. Adsorption Kinetics. To better understand the adsorption characteristics of $\mathrm{Pb}^{2+}$ and $\mathrm{Cd}^{2+}$ by HAp/chitosan hybrid fibers, we examined the adsorption kinetics for a representative sample (i.e., 30/70 HAp/chitosan hybrid fibers) from the metal ion removal curves over time using three metal ion adsorption models (e.g., pseudo-first-order kinetic, pseudosecond-order kinetic, and intraparticle diffusion model) [2630]. First, the kinetics of $\mathrm{Pb}^{2+}$ and $\mathrm{Cd}^{2+}$ adsorption on the 30/70 HAp/chitosan hybrid fibers was analyzed using Lagergren pseudo-first-order kinetic model [31] that can be expressed as

$$
\frac{d q_{t}}{d t}=k_{1}\left(q_{e}-q_{t}\right)
$$




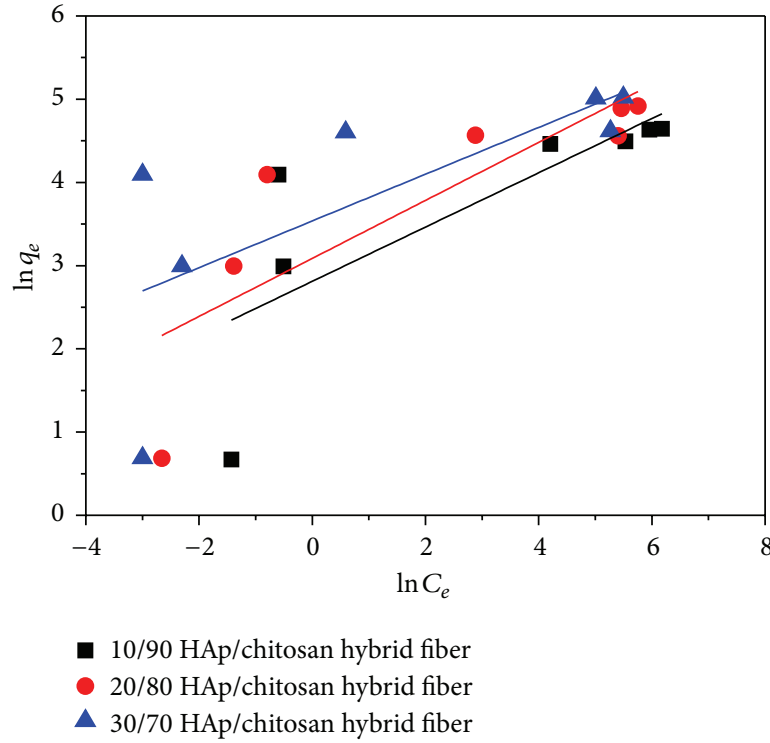

(a)

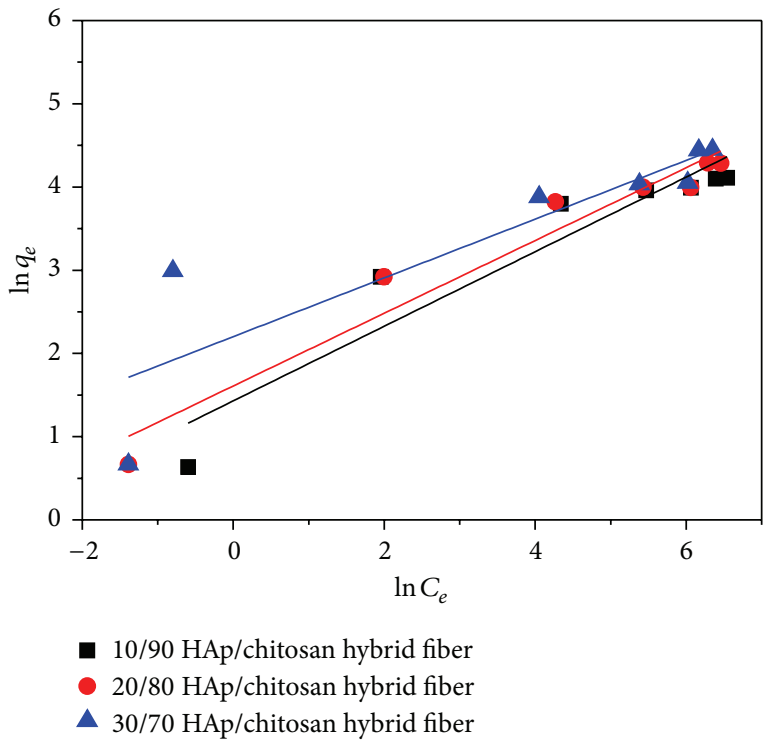

(b)

FiguRE 5: Freundlich isotherm model for adsorption of (a) $\mathrm{Pb}^{2+}$ and (b) $\mathrm{Cd}^{2+}$ on hybrid fibers with different HAp/chitosan ratio (10/90 (square), 20/80 (circle), and 30/70 (triangle)).

TABLE 2: Isotherm parameters for adsorption of $\mathrm{Pb}^{2+}$ and $\mathrm{Cd}^{2+}$ by HAp/chitosan hybrid fibers with different HAp contents.

\begin{tabular}{|c|c|c|c|c|c|c|c|}
\hline \multirow{2}{*}{ Metal ions } & \multirow{2}{*}{ HAp/chitosan } & \multicolumn{3}{|c|}{ Langmuir constants } & \multicolumn{3}{|c|}{ Freundlich constants } \\
\hline & & $q_{\max }(\mathrm{mg} / \mathrm{g})$ & $b(\mathrm{~L} / \mathrm{mg})$ & $r^{2}$ & $K_{F}\left(\mathrm{mg} / \mathrm{g}(\mathrm{mg} / \mathrm{L})^{-1 / n}\right)$ & $n$ & $r^{2}$ \\
\hline \multirow{3}{*}{$\mathrm{Pb}^{2+}$} & $10 / 90$ & 103.84 & 0.097 & 0.994 & 16.63 & 3.07 & 0.508 \\
\hline & $20 / 80$ & 126.26 & 0.153 & 0.945 & 21.90 & 2.87 & 0.624 \\
\hline & $30 / 70$ & 132.10 & 0.477 & 0.923 & 34.36 & 3.56 & 0.429 \\
\hline \multirow{3}{*}{$\mathrm{Cd}^{2+}$} & $10 / 90$ & 62.15 & 0.035 & 0.995 & 4.18 & 2.23 & 0.880 \\
\hline & $20 / 80$ & 72.25 & 0.025 & 0.953 & 5.00 & 2.29 & 0.938 \\
\hline & $30 / 70$ & 81.10 & 0.027 & 0.903 & 9.04 & 2.84 & 0.735 \\
\hline
\end{tabular}

where $q_{t}$ and $q_{e}$ are the adsorbed amounts $(\mathrm{mg} / \mathrm{g})$ at time $t(\mathrm{~h})$ and equilibrium, respectively, and $k_{1}\left(\mathrm{~h}^{-1}\right)$ is the firstorder Lagergren adsorption rate constant. This model can be linearized as

$$
\ln \left(q_{e}-q_{t}\right)=\ln q_{e}-k_{1} t
$$

Figures 6(a) and 6(b) show the pseudo-first-order plot of $\ln \left(q_{e}-q_{t}\right)$ versus $t$ for adsorption of $\mathrm{Pb}^{2+}$ and $\mathrm{Cd}^{2+}$ by the 30/70 HAp/chitosan hybrid fibers, respectively. The nonlinearity of the plots suggests that the adsorption process does not follow the pseudo-first-order kinetic mechanism. For quantitative comparison, the $k_{1}$ values for each case were determined and are given in Table 3 along with the correlation coefficient $\left(r^{2}\right)$, which clearly indicates that the pseudo-first-order kinetic model is not suitable to describe the $\mathrm{Pb}^{2+}$ and $\mathrm{Cd}^{2+}$ adsorption process.

A pseudo-second-order model has been reported to provide a better relationship for kinetics of metal ion adsorption process [26-29]. The pseudo-second-order kinetic model is expressed as

$$
\frac{d q_{t}}{d t}=k_{2}\left(q_{e}-q_{t}\right)^{2}
$$

with the second-order adsorption rate constant $k_{2}(\mathrm{~g} / \mathrm{mg} / \mathrm{h})$. The model can be linearized as

$$
\frac{t}{q_{t}}=\frac{1}{k_{2} q_{e}^{2}}+\frac{t}{q_{e}}
$$

$k_{2}$ and $r^{2}$ were determined from linear plots of $\left(t / q_{t}\right)$ versus $t$ curves (Figure 7). Table 4 shows the $k_{2}$ and $r^{2}$ values for the adsorption of $\mathrm{Pb}^{2+}$ and $\mathrm{Cd}^{2+}$ obtained from Figures 7(a) and $7(\mathrm{~b})$. The $r^{2}$ values for all the experimental conditions indicate that the pseudo-second-order model shows a better fit compared to the pseudo-first-order model. This indicates that the rate-limiting step could be chemisorption involving valency forces through the sharing or exchange of electrons 


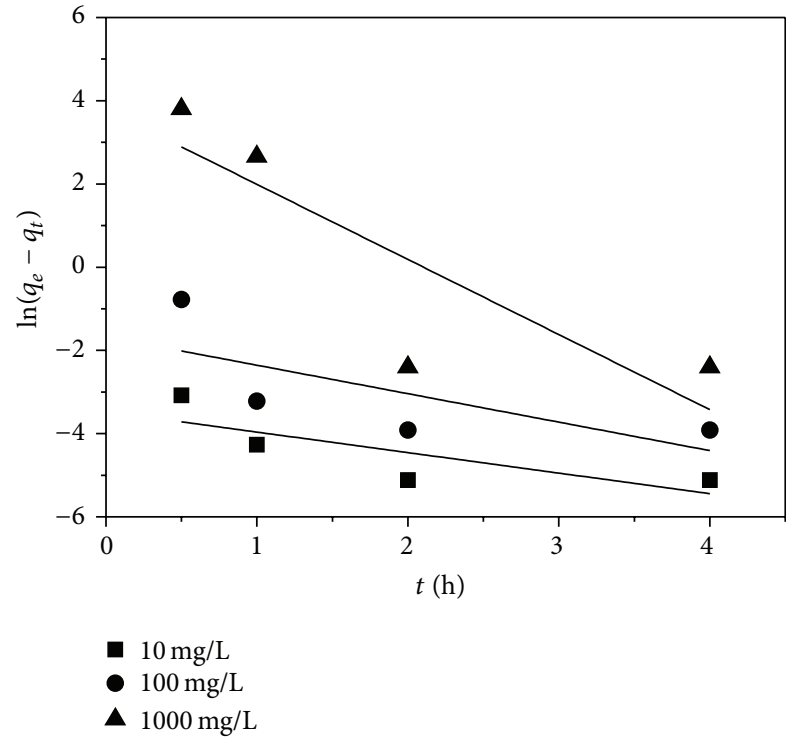

(a)

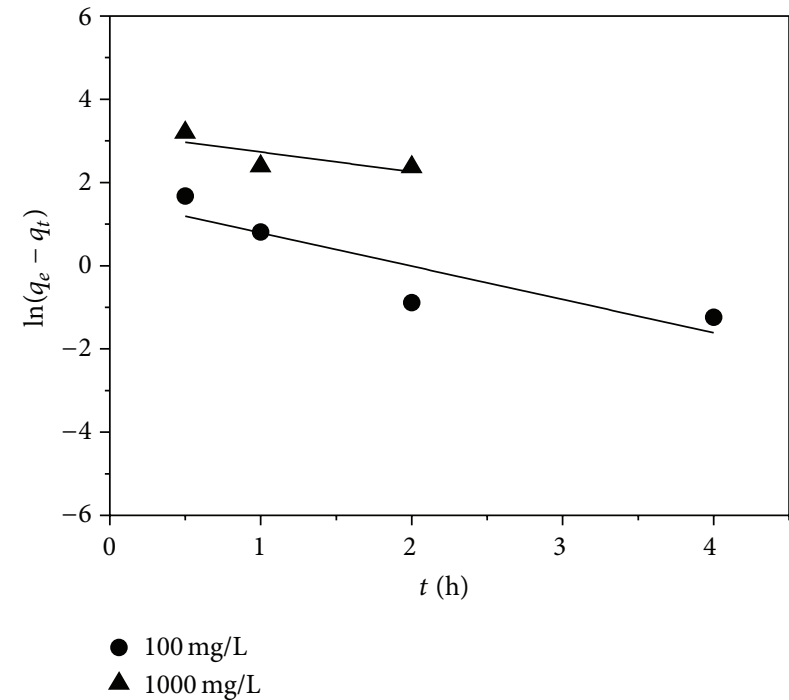

(b)

FIGURE 6: Pseudo-first-order kinetic model for adsorption of (a) $\mathrm{Pb}^{2+}$ and (b) $\mathrm{Cd}^{2+}$ on 30/70 HAp/chitosan hybrid fibers at initial metal ion concentration of $10 \mathrm{mg} / \mathrm{L}$ (square), $100 \mathrm{mg} / \mathrm{L}$ (circle), and $1000 \mathrm{mg} / \mathrm{L}$ (triangle).

TABle 3: Pseudo-first-order kinetic parameters for adsorption of $\mathrm{Pb}^{2+}$ and $\mathrm{Cd}^{2+}$ on $30 / 70 \mathrm{HAp} /$ chitosan hybrid fiber.

\begin{tabular}{|c|c|c|c|c|c|}
\hline \multirow{2}{*}{ Metal ions } & \multirow{2}{*}{ Initial concentration $(\mathrm{mg} / \mathrm{L})$} & \multirow{2}{*}{$q_{e, \exp }(\mathrm{mg} / \mathrm{g})^{\mathrm{a}}$} & \multicolumn{3}{|c|}{ Pseudo-first-order } \\
\hline & & & $q_{e, \mathrm{cal}}(\mathrm{mg} / \mathrm{g})^{\mathrm{b}}$ & $k_{1}\left(\mathrm{~h}^{-1}\right)$ & $r^{2}$ \\
\hline \multirow{3}{*}{$\mathrm{Pb}^{2+}$} & 10 & 1.99 & 0.03 & 0.49 & 0.439 \\
\hline & 100 & 19.98 & 0.19 & 0.68 & 0.259 \\
\hline & 1000 & 151.29 & 44.44 & 1.80 & 0.582 \\
\hline \multirow{3}{*}{$\mathrm{Cd}^{2+}$} & 10 & 1.95 & $\mathrm{ND}^{\mathrm{c}}$ & ND & $\mathrm{ND}$ \\
\hline & 100 & 19.91 & 4.90 & 0.80 & 0.700 \\
\hline & 1000 & 85.50 & 24.73 & 0.48 & 0.181 \\
\hline
\end{tabular}

${ }^{\mathrm{a}}$ Determined experimentally via (1).

${ }^{\mathrm{b}}$ Determined from Figure 6 via (5).

${ }^{c}$ Not determined.

TABLE 4: Pseudo-second-order kinetic parameters for adsorption of $\mathrm{Pb}^{2+}$ and $\mathrm{Cd}^{2+}$ on 30/70 HAp/chitosan hybrid fiber.

\begin{tabular}{|c|c|c|c|c|c|}
\hline \multirow{2}{*}{ Metal ions } & \multirow{2}{*}{ Initial concentration $(\mathrm{mg} / \mathrm{L})$} & \multirow{2}{*}{$q_{e, \exp }(\mathrm{mg} / \mathrm{g})^{\mathrm{a}}$} & \multicolumn{3}{|c|}{ Pseudo-second-order } \\
\hline & & & $q_{e, \mathrm{cal}}(\mathrm{mg} / \mathrm{g})^{\mathrm{b}}$ & $k_{2}(\mathrm{~g} / \mathrm{mg} / \mathrm{h})$ & $r^{2}$ \\
\hline \multirow{3}{*}{$\mathrm{Pb}^{2+}$} & 10 & 1.99 & 1.99 & 61.21 & 1 \\
\hline & 100 & 19.98 & 20.00 & 6.80 & 1 \\
\hline & 1000 & 151.29 & 159.49 & 0.03 & 0.998 \\
\hline \multirow{3}{*}{$\mathrm{Cd}^{2+}$} & 10 & 1.95 & 2.04 & 6.86 & 1 \\
\hline & 100 & 19.91 & 20.57 & 0.29 & 0.999 \\
\hline & 1000 & 85.50 & 90.25 & 0.04 & 0.994 \\
\hline
\end{tabular}

${ }^{\mathrm{a}}$ Determined experimentally via (1).

${ }^{\mathrm{b}}$ Determined from Figure 7 via (7).

between the adsorbent and adsorbate [32]. Similar trend was also observed from many previous studies [26-29].

If intraparticle diffusion is the rate-limiting step of the heavy metal ion adsorption, diffusion-related model should be used; however, the diffusion mechanism cannot be identified by the pseudo-first- and pseudo-second-order kinetic models. Hence, the intraparticle diffusion was analyzed by the rate equation expressed as [33]

$$
q_{t}=k_{\mathrm{id}} t^{1 / 2}+C
$$

where $C$ is the intercept and $k_{\mathrm{id}}$ is the intraparticle diffusion rate constant $\left(\mathrm{mg} / \mathrm{g} / \mathrm{h}^{1 / 2}\right)$. 


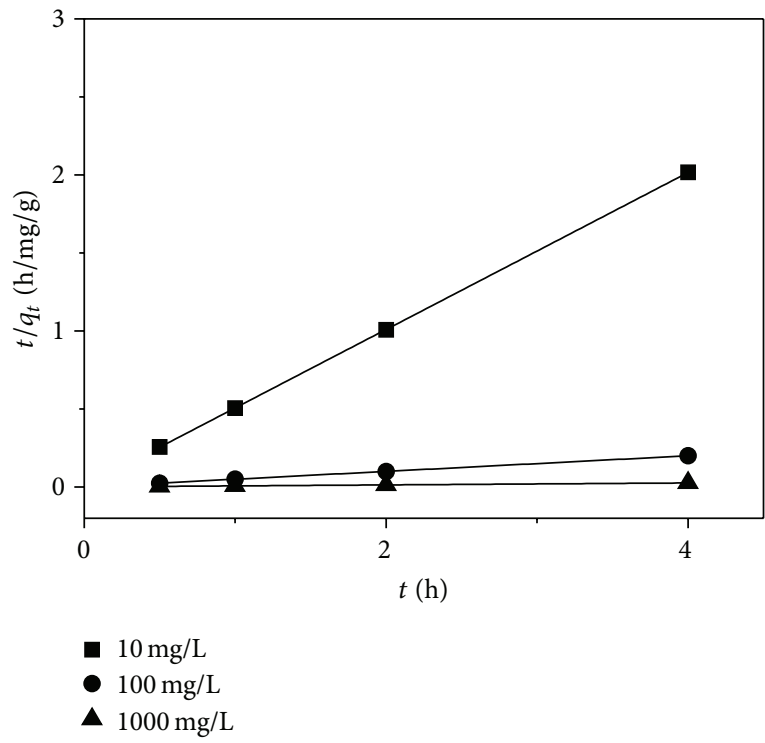

(a)

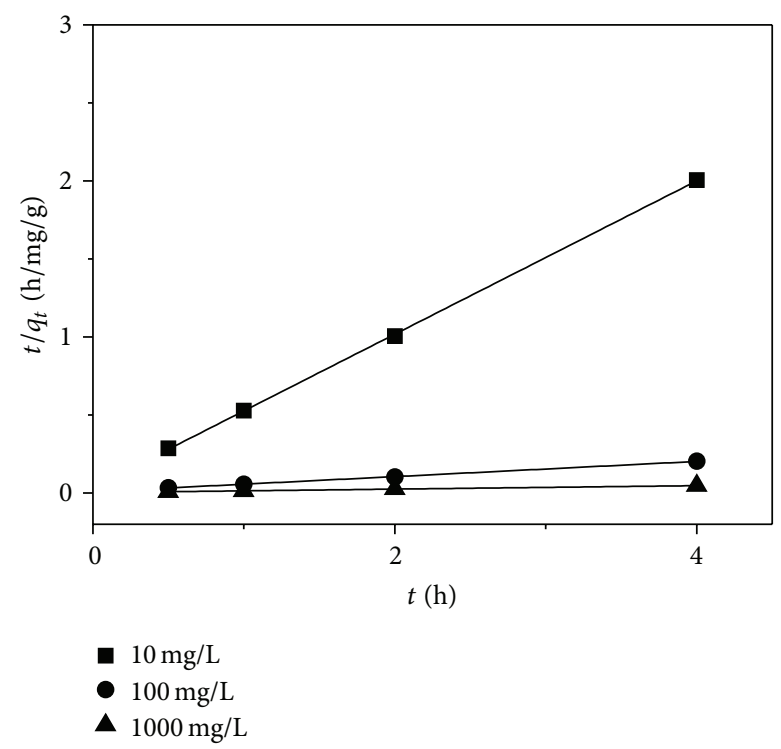

(b)

Figure 7: Pseudo-second-order kinetic model for adsorption of (a) $\mathrm{Pb}^{2+}$ and (b) $\mathrm{Cd}^{2+}$ on 30/70 HAp/chitosan hybrid fibers at initial metal ion concentration of $10 \mathrm{mg} / \mathrm{L}$ (square), $100 \mathrm{mg} / \mathrm{L}$ (circle), and $1000 \mathrm{mg} / \mathrm{L}$ (triangle).

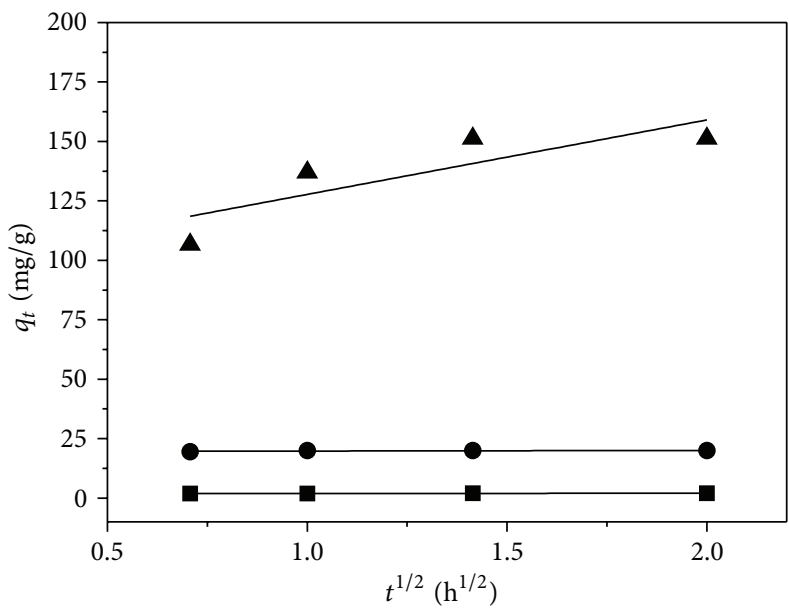

- $10 \mathrm{mg} / \mathrm{L}$

- $100 \mathrm{mg} / \mathrm{L}$

A $1000 \mathrm{mg} / \mathrm{L}$

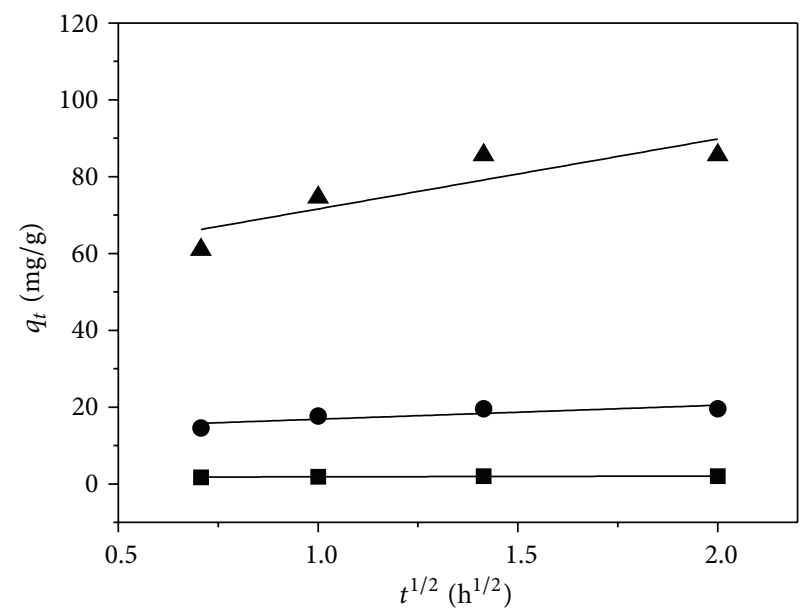

- $10 \mathrm{mg} / \mathrm{L}$

- $100 \mathrm{mg} / \mathrm{L}$

A $1000 \mathrm{mg} / \mathrm{L}$

(a)

(b)

Figure 8: Intraparticle diffusion model for adsorption of (a) $\mathrm{Pb}^{2+}$ and (b) $\mathrm{Cd}^{2+}$ on $30 / 70 \mathrm{HAp} /$ chitosan hybrid fibers at initial metal ion concentration of $10 \mathrm{mg} / \mathrm{L}$ (square), $100 \mathrm{mg} / \mathrm{L}$ (circle), and $1000 \mathrm{mg} / \mathrm{L}$ (triangle).

Figures $8(\mathrm{a})$ and $8(\mathrm{~b})$ show the intraparticle diffusion plot of $q_{t}$ versus $t^{1 / 2}$ for adsorption of $\mathrm{Pb}^{2+}$ and $\mathrm{Cd}^{2+}$ by the 30/70 HAp/chitosan hybrid fibers, respectively. The plots obtained by least-square fitting were observed not to have linear correlation with the experimentally observed data (see $r^{2}$ values in Table 5), indicating that the adsorption kinetics are not well predictable by the intraparticle diffusion model.

The kinetic studies for the 30/70 HAp/chitosan hybrid fiber revealed that the adsorption kinetics of heavy metals to the hybrid fiber likely follows the 


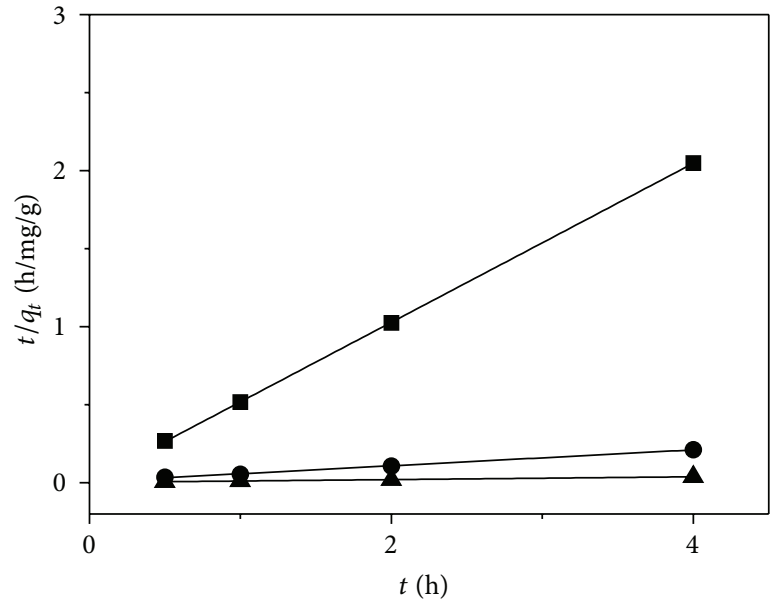

- $10 \mathrm{mg} / \mathrm{L}$

- $100 \mathrm{mg} / \mathrm{L}$

- $1000 \mathrm{mg} / \mathrm{L}$

(a) $\mathrm{Pb}^{2+}$

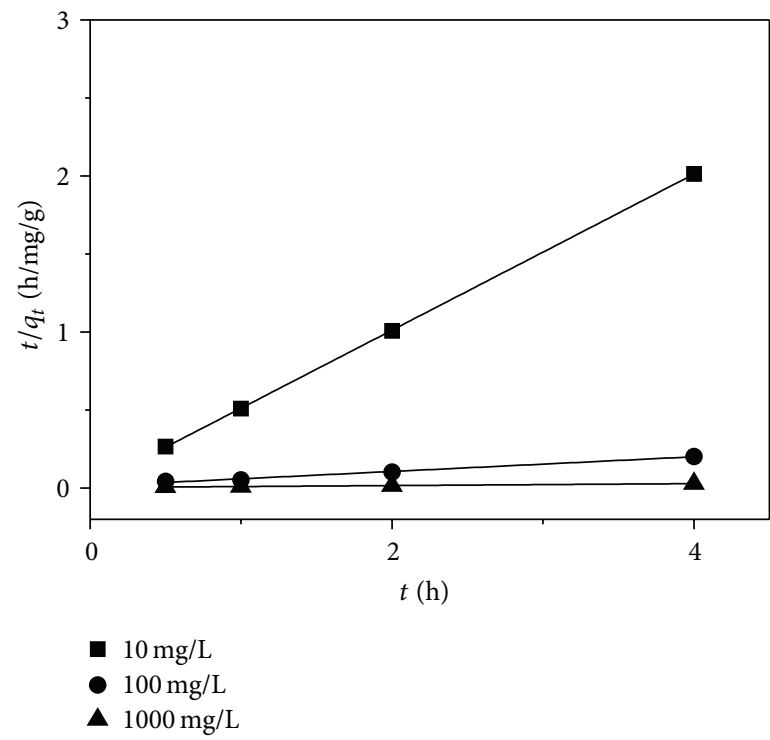

(c) $\mathrm{Pb}^{2+}$

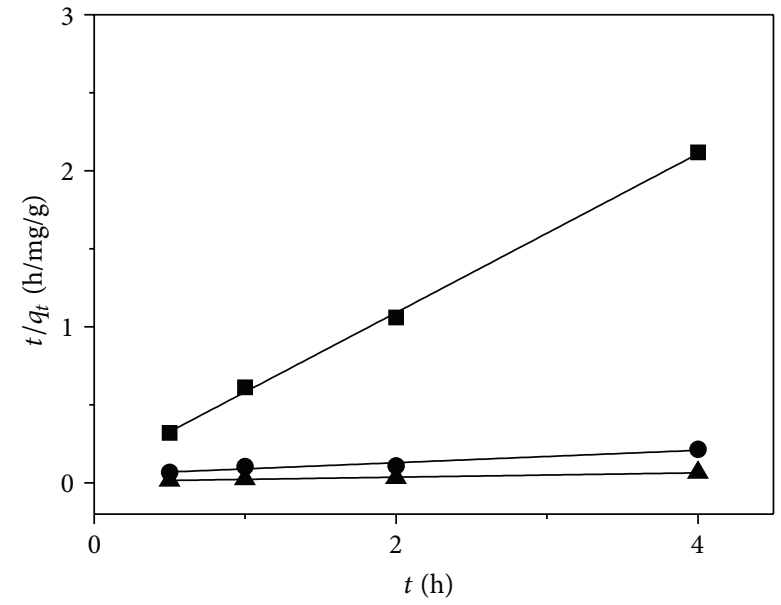

- $10 \mathrm{mg} / \mathrm{L}$

- $100 \mathrm{mg} / \mathrm{L}$

- $1000 \mathrm{mg} / \mathrm{L}$

(b) $\mathrm{Cd}^{2+}$

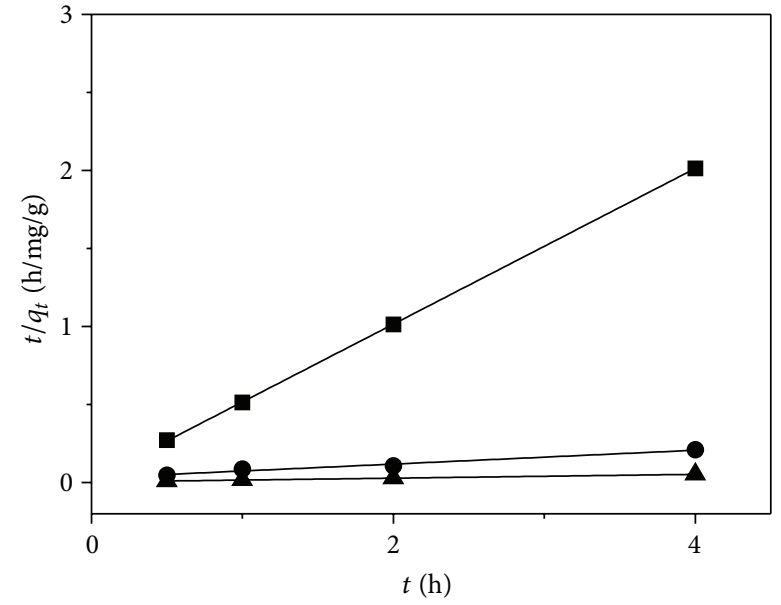

- $10 \mathrm{mg} / \mathrm{L}$

- $100 \mathrm{mg} / \mathrm{L}$

- $1000 \mathrm{mg} / \mathrm{L}$

FIGURE 9: Pseudo-second-order kinetic model for adsorption of $\mathrm{Pb}^{2+}$ and $\mathrm{Cd}^{2+}$ by the HAp/chitosan hybrid fibers: (a) and (b) 10/90, (c) and (d) 20/80 HAp/chitosan hybrid fibers.

TABLE 5: Intraparticle diffusion parameters for adsorption of $\mathrm{Pb}^{2+}$ and $\mathrm{Cd}^{2+}$ on $30 / 70 \mathrm{HAp} /$ chitosan hybrid fiber.

\begin{tabular}{lcccc}
\hline Metal ions & $\begin{array}{c}\text { Initial concentration } \\
(\mathrm{mg} / \mathrm{L})\end{array}$ & \multicolumn{3}{c}{ Intraparticle diffusion } \\
& $k_{\mathrm{id}}\left(\mathrm{mg} / \mathrm{g} / \mathrm{h}^{1 / 2}\right)$ & $C$ & $r^{2}$ \\
\hline \multirow{3}{*}{$\mathrm{Pb}^{2+}$} & 10 & 0.03 & 1.94 & 0.426 \\
& 100 & 0.27 & 19.49 & 0.249 \\
& 1000 & 31.33 & 96.39 & 0.547 \\
\hline \multirow{2}{*}{$\mathrm{Cd}^{2+}$} & 10 & 0.18 & 1.67 & 0.613 \\
& 100 & 3.65 & 13.20 & 0.607 \\
& 1000 & 18.22 & 53.37 & 0.648 \\
\hline
\end{tabular}

pseudo-second-order kinetic model. To further confirm that this kinetic model is valid for the hybrid fibers with different HAp contents, additional analyses were performed for the 10/90 and 20/80 HAp/chitosan content ratio of hybrid fibers using the pseudo-second-order kinetic model. The results are presented in Figures 9 (a)-9(d) $\left(\mathrm{Pb}^{2+}\right.$ by the $10 / 90$ and 20/80 HAp/chitosan hybrid fiber in Figures 9(a) and 9(c), and $\mathrm{Cd}^{2+}$ by the 10/90 and 20/80 HAp/chitosan hybrid fiber in Figures 9(b) and 9(d)) as well as Tables 6 and 7. The $r^{2}$ values clearly indicate that the $\mathrm{Pb}^{2+}$ and $\mathrm{Cd}^{2+}$ adsorption kinetics follows the pseudo-second-order model. 
TABLE 6: Pseudo-second-order kinetic parameters for adsorption of $\mathrm{Pb}^{2+}$ and $\mathrm{Cd}^{2+}$ on 10/90 HAp/chitosan hybrid fiber.

\begin{tabular}{|c|c|c|c|c|c|}
\hline \multirow{2}{*}{ Metal ions } & \multirow{2}{*}{ Initial concentration $(\mathrm{mg} / \mathrm{L})$} & \multirow{2}{*}{$q_{e, \exp }(\mathrm{mg} / \mathrm{g})^{\mathrm{a}}$} & \multicolumn{3}{|c|}{ Pseudo-second-order } \\
\hline & & & $q_{e, \mathrm{cal}}(\mathrm{mg} / \mathrm{g})^{\mathrm{b}}$ & $k_{2}(\mathrm{~g} / \mathrm{mg} / \mathrm{h})$ & $r^{2}$ \\
\hline \multirow{3}{*}{$\mathrm{Pb}^{2+}$} & 10 & 1.95 & 1.96 & 27.64 & 1 \\
\hline & 100 & 19.88 & 19.63 & 0.38 & 0.997 \\
\hline & 1000 & 103.88 & 111.48 & 0.03 & 0.995 \\
\hline \multirow{3}{*}{$\mathrm{Cd}^{2+}$} & 10 & 1.89 & 1.96 & 3.52 & 0.998 \\
\hline & 100 & 18.59 & 25.18 & 0.32 & 0.911 \\
\hline & 1000 & 61.10 & 71.94 & 0.02 & 0.979 \\
\hline
\end{tabular}

${ }^{a}$ Determined experimentally via (1).

${ }^{b}$ Determined from Figure 9 via (7).

TABLE 7: Pseudo-second-order kinetic parameters for adsorption of $\mathrm{Pb}^{2+}$ and $\mathrm{Cd}^{2+}$ on 20/80 HAp/chitosan hybrid fiber.

\begin{tabular}{|c|c|c|c|c|c|}
\hline \multirow{2}{*}{ Metal ions } & \multirow{2}{*}{ Initial concentration $(\mathrm{mg} / \mathrm{L})$} & \multirow{2}{*}{$q_{e, \exp }(\mathrm{mg} / \mathrm{g})^{\mathrm{a}}$} & \multicolumn{3}{|c|}{ Pseudo-second-order } \\
\hline & & & $q_{e, \mathrm{cal}}(\mathrm{mg} / \mathrm{g})^{\mathrm{b}}$ & $k_{2}(\mathrm{~g} / \mathrm{mg} / \mathrm{h})$ & $r^{2}$ \\
\hline \multirow{3}{*}{$\mathrm{Pb}^{2+}$} & 10 & 1.99 & 2.00 & 20.26 & 1 \\
\hline & 100 & 19.95 & 21.24 & 0.18 & 0.988 \\
\hline & 1000 & 137.00 & 161.29 & 0.01 & 0.983 \\
\hline \multirow{3}{*}{$\mathrm{Cd}^{2+}$} & 10 & 1.95 & 2.01 & 13.83 & 1 \\
\hline & 100 & 18.53 & 22.54 & 0.07 & 0.969 \\
\hline & 1000 & 72.61 & 81.90 & 0.04 & 0.995 \\
\hline
\end{tabular}

${ }^{a}$ Determined experimentally via (1).

${ }^{\mathrm{b}}$ Determined from Figure 9 via (7).

\section{Conclusions}

Based on the present study, the following conclusions can be drawn:

(i) HAp/chitosan hybrid fibers with different contents of HAp were prepared successfully by a wet spinning method.

(ii) Removal performance of heavy metal ions $\left(\mathrm{Pb}^{2+}\right.$ and $\mathrm{Cd}^{2+}$ ) was improved for HAp/chitosan hybrid fibers compared to chitosan fibers.

(iii) Removal performance of heavy metal ions $\left(\mathrm{Pb}^{2+}\right.$ and $\mathrm{Cd}^{2+}$ ) was strongly affected by several parameters, such as initial metal concentration, reaction time, and HAp content in the fiber. In particular, the removal capacity for the heavy metal ions increased with increasing HAp content in the HAp/chitosan hybrid fibers due to the increase of the specific surface area.

(iv) Adsorption kinetic and isotherm tests showed that $\mathrm{Pb}^{2+}$ and $\mathrm{Cd}^{2+}$ adsorption to the hybrid fiber follows pseudo-second-order kinetic model (i.e., chemisorption) and Langmuir-type adsorption, respectively.

\section{Conflict of Interests}

The authors declare that there is no conflict of interests regarding the publication of this paper.

\section{Acknowledgments}

This work was supported by the National Research Foundation of Korea Grant funded by the Korean Government (MEST) (NRF-2011-0014627) and by Grant no. RTI104-01-04 from the Regional Technology Innovation Program of the Ministry of Knowledge Economy (MKE).

\section{References}

[1] P. F. Gomes, P. R. Lennartsson, N.-K. Persson, and M. J. Taherzadeh, "Heavy metal biosorption by Rhizopus Sp. biomass immobilized on textiles," Water, Air, \& Soil Pollution, vol. 225, no. 2, article 1834, 2014

[2] J. L. Wang and C. Chen, "Biosorbents for heavy metals removal and their future," Biotechnology Advances, vol. 27, no. 2, pp. 195226, 2009.

[3] S. E. Bailey, T. J. Olin, R. M. Bricka, and D. D. Adrian, "A review of potentially low-cost sorbents for heavy metals," Water Research, vol. 33, no. 11, pp. 2469-2479, 1999.

[4] F. L. Fu and Q. Wang, "Removal of heavy metal ions from wastewaters: a review," Journal of Environmental Management, vol. 92, no. 3, pp. 407-418, 2011.

[5] D. Mohan, H. Kumar, A. Sarswat, M. Alexandre-Franco, and C. U. Pittman, "Cadmium and lead remediation using magnetic oak wood and oak bark fast pyrolysis bio-chars," Chemical Engineering Journal, vol. 236, pp. 513-528, 2014.

[6] K. Kandori, H. Hamazaki, M. Matsuzawa, and S. Togashi, "Selective adsorption of acidic protein of bovine serum albumin onto sheet-like calcium hydroxyapatite particles produced by microreactor," Advanced Powder Technology, vol. 25, no. 1, pp. 354-359, 2014. 
[7] D.-L. Trandafir, C. Mirestean, R. V. F. Turcu, B. Frentiu, D. Eniu, and S. Simon, "Structural characterization of nanostructured hydroxyapatite-iron oxide composites," Ceramics International, vol. 40, no. 7, pp. 11071-11078, 2014.

[8] S. Bailliez, A. Nzihou, E. Bèche, and G. Flamant, "Removal of lead $(\mathrm{Pb})$ by hydroxyapatite sorbent," Process Safety and Environmental Protection, vol. 82, no. 2 B, pp. 175-180, 2004.

[9] A. Corami, S. Mignardi, and V. Ferrini, "Copper and zinc decontamination from single- and binary-metal solutions using hydroxyapatite," Journal of Hazardous Materials, vol. 146, no. 12, pp. 164-170, 2007.

[10] I. Mobasherpour, E. Salahi, and M. Pazouki, "Removal of nickel (II) from aqueous solutions by using nano-crystalline calcium hydroxyapatite," Journal of Saudi Chemical Society, vol. 15, no. 2, pp. 105-112, 2011.

[11] I. Smičiklas, S. Dimović, I. Plećaš, and M. Mitrić, "Removal of $\mathrm{Co}^{2+}$ from aqueous solutions by hydroxyapatite," Water Research, vol. 40, no. 12, pp. 2267-2274, 2006.

[12] R. H. Zhu, R. B. Yu, J. X. Yao, D. Mao, C. J. Xing, and D. Wang, "Removal of $\mathrm{Cd}^{2+}$ from aqueous solutions by hydroxyapatite," Catalysis Today, vol. 139, no. 1-2, pp. 94-99, 2008.

[13] S. Choi and Y. Jeong, "The removal of heavy metals in aqueous solution by hydroxyapatite/cellulose composite," Fibers and Polymers, vol. 9, no. 3, pp. 267-270, 2008.

[14] Y. Han, J. Choi, M. Tong, and H. Kim, "Synthesis and characterization of high-surface-area millimeter-sized silica beads with hierarchical multi-modal pore structure by the addition of agar," Materials Characterization, vol. 90, pp. 31-39, 2014.

[15] M. Aliabadi, M. Irani, J. Ismaeili, and S. Najafzadeh, "Design and evaluation of chitosan/hydroxyapatite composite nanofiber membrane for the removal of heavy metal ions from aqueous solution," Journal of the Taiwan Institute of Chemical Engineers, vol. 45, no. 2, pp. 518-526, 2014.

[16] E. Guibal, "Interactions of metal ions with chitosan-based sorbents: a review," Separation and Purification Technology, vol. 38, no. 1, pp. 43-74, 2004.

[17] J. L. Wang and C. Chen, "Chitosan-based biosorbents: modification and application for biosorption of heavy metals and radionuclides," Bioresource Technology, vol. 160, pp. 129-141, 2014.

[18] I. Yamaguchi, K. Tokuchi, H. Fukuzaki et al., "Preparation and microstructure analysis of chitosan/hydroxyapatite nanocomposites," Journal of Biomedical Materials Research, vol. 55, no. 1, pp. 20-27, 2001.

[19] C. Y. Zhang, J. Chen, Z. Zhuang, T. Zhang, X. P. Wang, and Q. F. Fang, "In situ hybridization and characterization of fibrous hydroxyapatite/chitosan nanocomposite," Journal of Applied Polymer Science, vol. 124, no. 1, pp. 397-402, 2012.

[20] S. Babel and T. A. Kurniawan, "Low-cost adsorbents for heavy metals uptake from contaminated water: a review," Journal of Hazardous Materials, vol. 97, no. 1-3, pp. 219-243, 2003.

[21] Z. Dong, D. Wang, X. Liu, X. Pei, L. Chen, and J. Jin, "Bioinspired surface-functionalization of graphene oxide for the adsorption of organic dyes and heavy metal ions with a superhigh capacity," Journal of Materials Chemistry A, vol. 2, no. 14, pp. 5034-5040, 2014.

[22] I. Mobasherpour, E. Salahi, and M. Pazouki, "Comparative of the removal of $\mathrm{Pb}^{2+}, \mathrm{Cd}^{2+}$, and $\mathrm{Ni}^{2+}$ by nano crystallite hydroxyapatite from aqueous solutions: adsorption isotherm study," Arabian Journal of Chemistry, vol. 5, no. 4, pp. 439-446, 2012.
[23] Z. Zhang, M. Li, W. Chen, S. Zhu, N. Liu, and L. Zhu, "Immobilization of lead and cadmium from aqueous solution and contaminated sediment using nano-hydroxyapatite," Environmental Pollution, vol. 158, no. 2, pp. 514-519, 2010.

[24] I. Langmuir, "The adsorption of gases on plane surfaces of glass, mica and platinum," The Journal of the American Chemical Society, vol. 40, no. 9, pp. 1361-1403, 1918.

[25] H. Freundlich, "Adsorption in solution," The Journal of Physical Chemistry, vol. 40, pp. 1361-1368, 1906.

[26] M. Aliabadi, K. Morshedzadeh, and H. Soheyli, "Removal of hexavalent chromium from aqueous solution by lignocellulosic solid wastes," International Journal of Environmental Science and Technology, vol. 3, no. 3, pp. 321-325, 2006.

[27] M. A. Hossain, M. Kumita, Y. Michigami, and S. Mori, "Kinetics of $\mathrm{Cr}(\mathrm{VI})$ adsorption on used black tea leaves," Journal of Chemical Engineering of Japan, vol. 38, no. 6, pp. 402-408, 2005.

[28] M. Pérez-Candela, J. Martín-Martínez, and R. TorregrosaMaciá, "Chromium(VI) removal with activated carbons," Water Research, vol. 29, no. 9, pp. 2174-2180, 1995.

[29] K. Periasamy, K. Srinivasan, and P. R. Muruganan, "Studies on chromium(VI) removal by activated ground nut husk carbon," Indian Journal of Environmental Health, vol. 33, pp. 433-439, 1991.

[30] K. Mohanty, M. Jha, B. C. Meikap, and M. N. Biswas, "Removal of chromium (VI) from dilute aqueous solutions by activated carbon developed from Terminalia arjuna nuts activated with zinc chloride," Chemical Engineering Science, vol. 60, no. 11, pp. 3049-3059, 2005.

[31] S. Lagergren, "About the theory of so called adsorption of soluble substances," Kungliga Svenska Vetenskapsakademiens Handlingar, vol. 24, pp. 1-6, 1898.

[32] Y. S. Ho and G. McKay, "Pseudo-second order model for sorption processes," Process Biochemistry, vol. 34, no. 5, pp. 451465, 1999.

[33] W. J. Weber and J. C. Morris, "Kinetics of adsorption on carbon from solution," Journal of the Sanitary Engineering DivisionAmerican Society of Civil Engineers, vol. 89, pp. 31-60, 1963. 

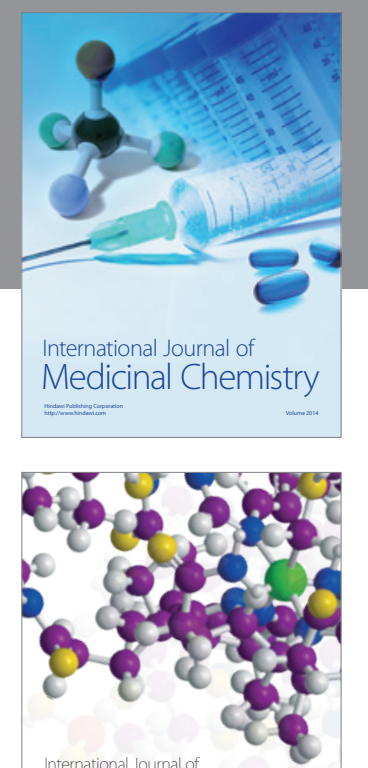

\section{Carbohydrate} Chemistry

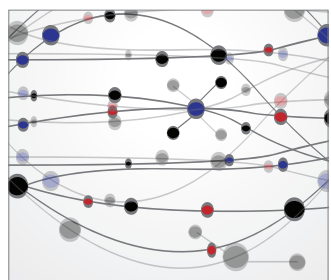

The Scientific World Journal
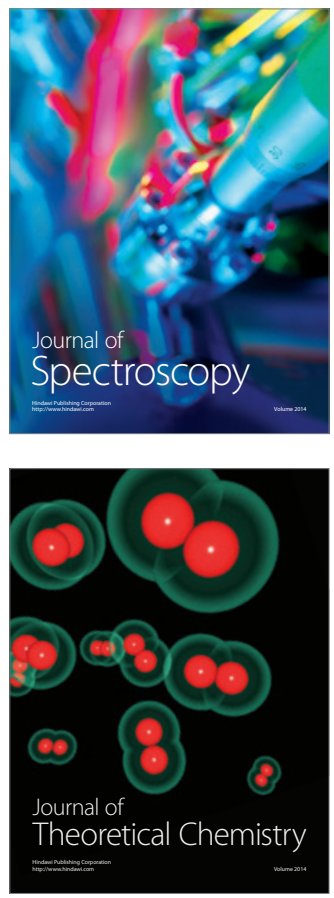
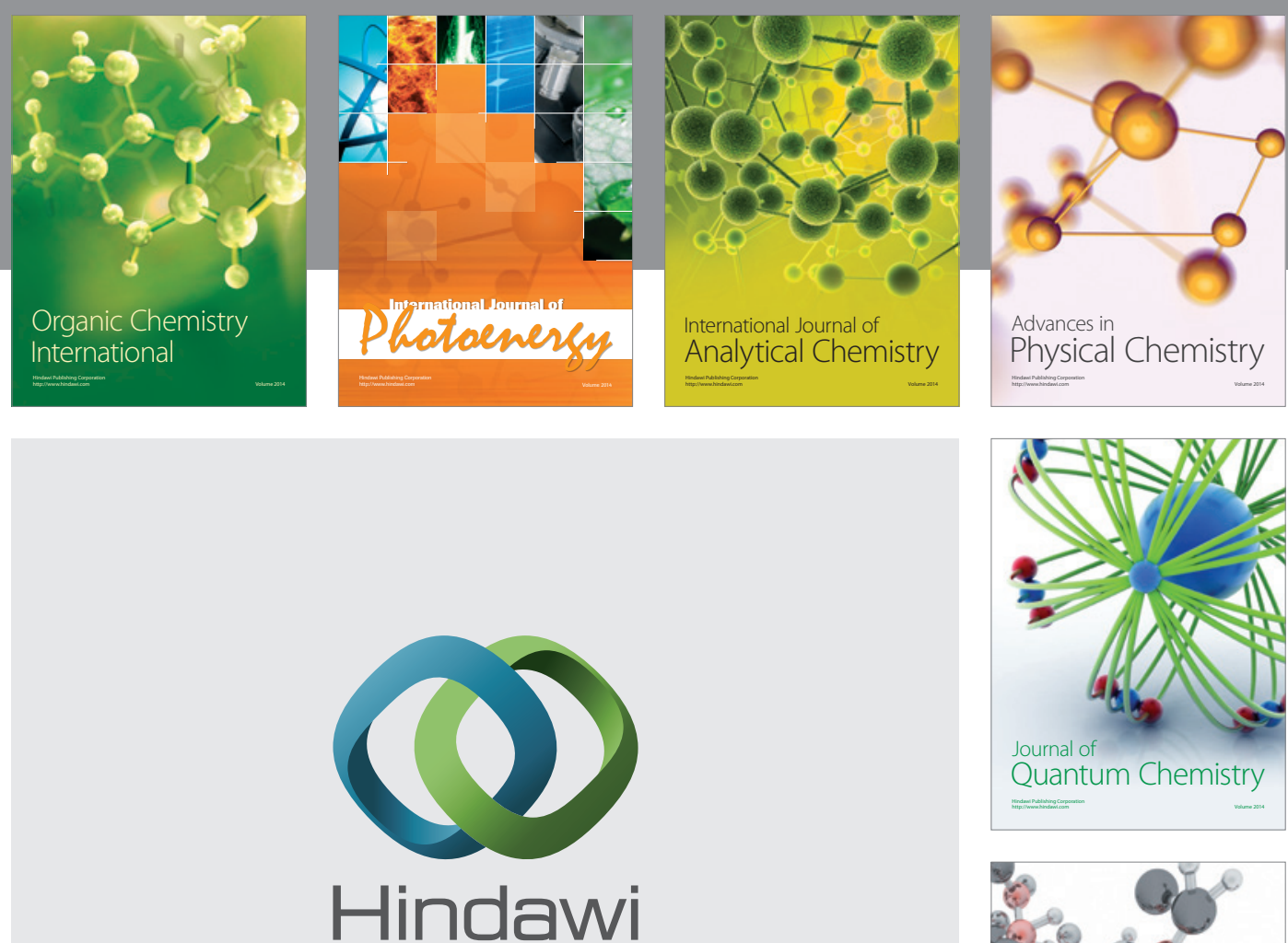

Submit your manuscripts at

http://www.hindawi.com

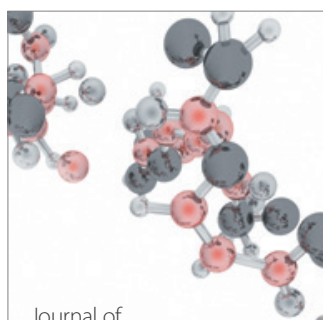

Analytical Methods

in Chemistry

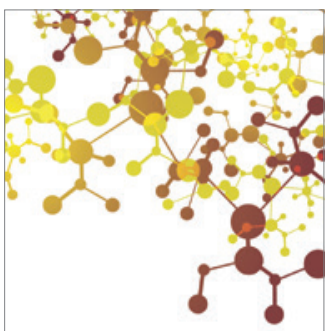

Journal of

Applied Chemistry

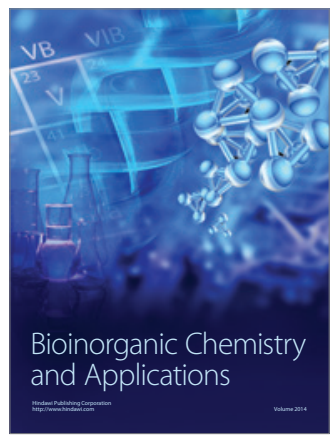

Inorganic Chemistry
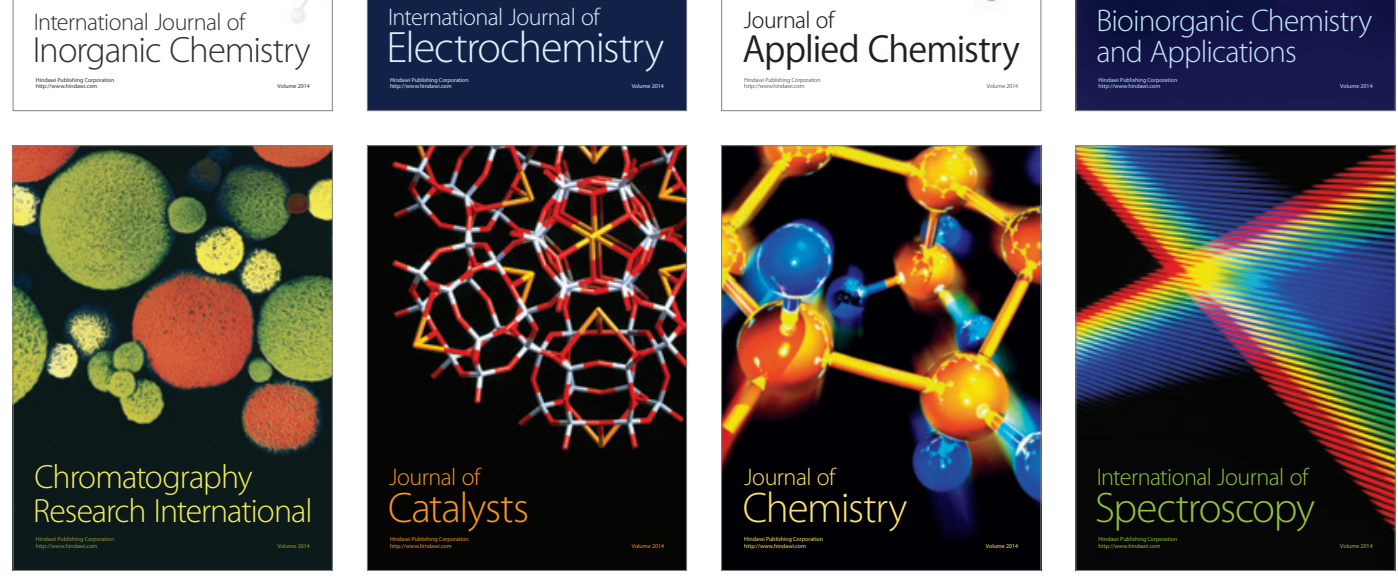